\title{
The comparison of dexamethasone and triamcinolone periarticular administration in total knee arthroplasty: retrospective cohort study
}

\author{
Atsufumi Oshima ${ }^{1,2^{*}}$, Kazuhisa Hatayama ${ }^{1}$, Masanori Terauchi ${ }^{1}$, Hibiki Kakiage ${ }^{1,2}$, Shogo Hashimoto ${ }^{2}$ and \\ Hirotaka Chikuda²
}

\begin{abstract}
Background: Intraoperative periarticular injection of corticosteroid effectively reduces perioperative pain in total knee arthroplasty (TKA). However, which corticosteroid is most effective for intraoperative periarticular injection remains controversial. We compared the effects of corticosteroids between dexamethasone and triamcinolone acetonide periarticular administration for reducing pain and postoperative nausea and increasing fasting blood glucose concentrations during the perioperative period following TKA.
\end{abstract}

Methods: One hundred and two patients who underwent TKA from August 2018 to September 2020 were divided into two groups: one received $10 \mathrm{mg}$ dexamethasone for intraoperative periarticular injection and another receiving $40 \mathrm{mg}$ triamcinolone acetonide. Postoperative pain scores at rest and during walking and nausea scores were recorded using a 0-to-10 Numerical Rating Scale. C-reactive protein (CRP) and fasting blood glucose levels were measured pre- and postoperatively.

Results: Pain scores in the triamcinolone group were significantly lower than in the dexamethasone group at rest 7 days postoperatively (1.5 vs. 2.0; $p=0.046$ ) and while walking at both $72 \mathrm{~h}(3.9 \mathrm{vs} .4 .8 ; p=0.008$ ) and 7 days postoperatively (3.2 vs. 4.0; $p=0.03$ ). The CRP levels in the triamcinolone group were significantly lower than in the dexamethasone group at 7 days postoperatively $(1.6 \mathrm{mg} / \mathrm{dl}$ vs. $3.0 \mathrm{mg} / \mathrm{dl}: p<0.001)$. The fasting blood glucose levels at 1 day postoperatively were increased in both groups but not significantly different between the groups. No significant differences in the nausea score were noted between the groups.

Conclusions: Triamcinolone acetonide periarticular administration provided greater pain relief by reducing inflammation to a greater degree than dexamethasone.

Keywords: Total knee arthroplasty, Periarticular injection, Corticosteroid, Dexamethasone, Triamcinolone acetonide

*Correspondence: aoshima@gunma-u.ac.jp

${ }^{1}$ Department of Orthopaedic Surgery, Japan Community Health Care

Organization Gunma Central Hospital, 1-7-13 Koun-cho, Maebashi,

Gunma 371-0025, Japan

2 Department of Orthopaedic Surgery, Gunma University Graduate School

of Medicine, 3-39-15 Showa-machi, Maebashi, Gunma 371-8511, Japan

Full list of author information is available at the end of the article

\section{Background}

Intraoperative administration of corticosteroid during total knee arthroplasty (TKA) has been reported to reduce perioperative pain and prevent nausea [1-8], and the routes of administration include intravenous and periarticular administration.

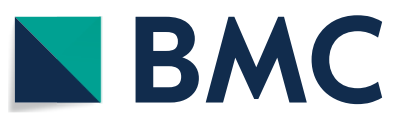

(c) The Author(s) 2022. Open Access This article is licensed under a Creative Commons Attribution 4.0 International License, which permits use, sharing, adaptation, distribution and reproduction in any medium or format, as long as you give appropriate credit to the original author(s) and the source, provide a link to the Creative Commons licence, and indicate if changes were made. The images or other third party material in this article are included in the article's Creative Commons licence, unless indicated otherwise in a credit line to the material. If material is not included in the article's Creative Commons licence and your intended use is not permitted by statutory regulation or exceeds the permitted use, you will need to obtain permission directly from the copyright holder. To view a copy of this licence, visit http://creativecommons.org/licenses/by/4.0/. The Creative Commons Public Domain Dedication waiver (http://creativeco mmons.org/publicdomain/zero/1.0/) applies to the data made available in this article, unless otherwise stated in a credit line to the data. 
A few studies thus far have compared the effects of intravenous and periarticular corticosteroid administration during TKA. These studies suggested that periarticular administration was recommended over intravenous administration for postoperative pain relief $[9,10]$. However, no studies have yet determined which steroids are most effective with periarticular administration during TKA. For example, in rheumatoid arthritis, intra-articular injection of $8 \mathrm{mg}$ dexamethasone and $40 \mathrm{mg}$ triamcinolone acetonide was reported to reduce knee joint pain and swelling significantly, but no significant differences in knee pain between the two groups were noted [11].

In addition, referring to the concern of hyperglycemia caused by the administration of corticosteroids, a previous study showed that the fasting blood glucose levels of the patients treated with triamcinolone acetonide periarticular injections were significantly increased the morning after TKA [9]. Several other studies have further reported that the intravenous administration of dexamethasone did not increase fasting blood glucose levels postoperatively following TKA $[1,12]$. However, no studies have yet described the effects of periarticular injections of dexamethasone on blood glucose levels after TKA.

Given the above, the present study compared the corticosteroid effects of periarticular injection between dexamethasone and triamcinolone acetonide on reducing pain and postoperative nausea and increasing fasting blood glucose levels during the perioperative period in TKA. We hypothesized that triamcinolone acetonide would provide greater pain relief by reducing inflammation to a greater degree than dexamethasone.

\section{Methods}

After receiving approval from the institutional review board, we retrospectively identified two cohorts of patients who had undergone unilateral TKA from August 2018 to October 2020. The triamcinolone group included 50 patients from the previous randomized controlled study [9]. After completion of the study, we added 52 patients to the dexamethasone group based on the same criteria. The inclusion criteria were (1) primary unilateral TKA for osteoarthritis of the knee and (2) age 55 to 90 years old. The exclusion criteria were patients with (1) a history of contralateral TKA within one year, (2) the administration of any glucocorticoids during the three months prior to the surgical procedure, (3) diabetes mellitus, (4) rheumatoid arthritis, (5) a history of knee surgery or knee injury for example high tibial osteotomy, meniscus repair, ligament reconstruction and so on (6) liver or renal failure (7) administration of any anticoagulant drug, and (8) preoperative deep venous thrombosis (DVT).
In the dexamethasone group, at the period from May 2020 to October 2020, a periarticular injection of $60 \mathrm{~mL}$ of physiological saline solution containing $10 \mathrm{mg}$ dexamethasone, which has been confirmed to be an effective dose, [5] and $150 \mathrm{mg}$ ropivacaine was administered during TKA.

In the triamcinolone group, at the period from August 2018 to May 2020, a periarticular injection of $60 \mathrm{~mL}$ of physiological saline solution containing $40 \mathrm{mg}$ triamcinolone acetonide, which has been confirmed to be an effective dose, [13] and $150 \mathrm{mg}$ ropivacaine was administered. The biological half-lives of dexamethasone and triamcinolone acetonide are 36 to $55 \mathrm{~h}$ and 18 to $36 \mathrm{~h}$, respectively, and $40 \mathrm{mg}$ of triamcinolone has an antiinflammatory potency equivalent to $8 \mathrm{mg}$ of dexamethasone $[2,14,15]$.

All TKA procedures were performed under general anesthesia. A single-shot, echo-guided femoral nerve block consisting of $20 \mathrm{~mL}$ of physical saline solution containing $75 \mathrm{mg}$ ropivacaine was performed for all patients before the surgical procedure. Two senior surgeons performed or assisted in all surgical procedures. A pneumatic tourniquet was inflated to $250 \mathrm{mmHg}$. Medial parapatellar arthrotomy was performed. An Attune prosthesis (Depuy, Warsaw, IN, USA) was implanted in all knees using cement. Just before the prosthesis was implanted, $20 \mathrm{~mL}$ of the mixture was injected into the posterior aspect of the capsule and the remaining $40 \mathrm{~mL}$ was injected into the synovium, periosteum, iliotibial band, and collateral ligaments. After capsule closure, all patients were administered an intra-articular injection of $2 \mathrm{~g}$ tranexamic acid in $20 \mathrm{~mL}$ of physiological saline solution to reduce blood loss. The tourniquet was released after the wound had been closed and the knee bandage had been wrapped. No drain was inserted in any cases.

Pain and nausea control were performed similarly in all patients. From the day after surgery, $1 \mathrm{~g}$ acetaminophen was taken orally 3 times a day. For the management of pain, an intramuscular injection of $15 \mathrm{mg}$ pentazocine and transrectal administration of $25 \mathrm{mg}$ diclofenac were given if the patient required rescue. For the management of nausea, an intramuscular injection of $10 \mathrm{mg}$ metoclopramide was given if the patient requested it. All patients were allowed to walk with a walker on the day after surgery. The number of uses of rescue analgesia and metoclopramide was recorded for $24 \mathrm{~h}$ postoperatively. Pain scores at rest, pain scores during walking, and nausea scores were recorded using a 0-to-10 Numerical Rating Scale, with pain at rest recorded at $4,8,16,24,48$, and $72 \mathrm{~h}$ and 7 days postoperatively; pain during walking at 24,48 , and $72 \mathrm{~h}$ and 7 days postoperatively; and nausea at 8,24 and $48 \mathrm{~h}$ postoperatively. The number of patients who vomited within $24 \mathrm{~h}$ after surgery was recorded. 
Patient temperatures were measured every $6 \mathrm{~h}$ for $72 \mathrm{~h}$ after surgery, and patients who had a high fever over $38^{\circ} \mathrm{C}$ at any point were recorded.

Demographic information, including the age, sex, body weight, height and operative time, were recorded. CRP and fasting blood glucose levels were determined within three weeks preoperatively. Fasting blood glucose levels were determined the morning after surgery. CRP levels were determined 24 and $48 \mathrm{~h}$ and 7 days postoperatively.

Based on the results of previous studies, $[2,16]$ an a priori power analysis was performed to detect a difference in pain score of 0.8 with the desired power of 0.90 and a significance level of 0.05 . The required sample size was calculated as 40 for each arm of the study. Assuming a $10 \%$ exclusion rate, the minimum sample size was 44 in each group. We included over 50 patients in each group (Fig. 1).

All statistical analyses were performed using the SPSS software program (SPSS version 26.0; IBM, International Business Machines Corporation, Armonk, NY, USA). Student's $t$-test was used to compare the age, body weight, height, operative time, CRP level, and fasting blood glucose level between the groups. The chi-square test was used to compare the sex, incidence of a postoperative fever, and incidence of vomiting between the groups. The Mann-Whitney U-test was used to compare the pain and nausea scores and number of times rescue analgesia and metoclopramide were used between the groups. For all parameters other than the pain score, a post hoc analysis was performed to confirm the power of the test with significant differences.

\section{Result}

Fifty-two patients were allocated to the dexamethasone group, and 50 patients were allocated to the triamcinolone group (Fig. 1). Preoperative fasting blood glucose levels were significantly higher in the triamcinolone group than in the dexamethasone group, but other demographic characteristics and preoperative laboratory data showed no significant differences between the groups (Table 1).

The pain scores in triamcinolone group were significantly lower than those in the dexamethasone group at rest at 7 days after surgery (mean and standard deviation, $1.5 \pm 1.5$ vs. $2.0 \pm 1.5 ; p=0.046$ ) (Fig. 2 ) and while walking both at $72 \mathrm{~h}(3.9 \pm 1.7$ vs. $4.8 \pm 1.7 ; p=0.008)$ and at 7 days after surgery. $(3.2 \pm 1.4$ vs. $4.0 \pm 1.7 ; p=0.03)$ (Fig. 3) There were no significant differences in the number of uses of rescue analgesia between the two groups (Table 2).

CRP in the triamcinolone group is significantly lower than in the dexamethasone group at 7 days after surgery. $(1.6 \pm 1.3 \mathrm{mg} / \mathrm{dl}$ vs. $3.0 \pm 2.2 \mathrm{mg} / \mathrm{dl}: p<0.001:$ post hoc power 0.98 ) (Fig. 4). Four patients (7.7\%) had a fever in the dexamethasone group, whereas $2(4 \%)$ had a fever in the triamcinolone group. There were no significant

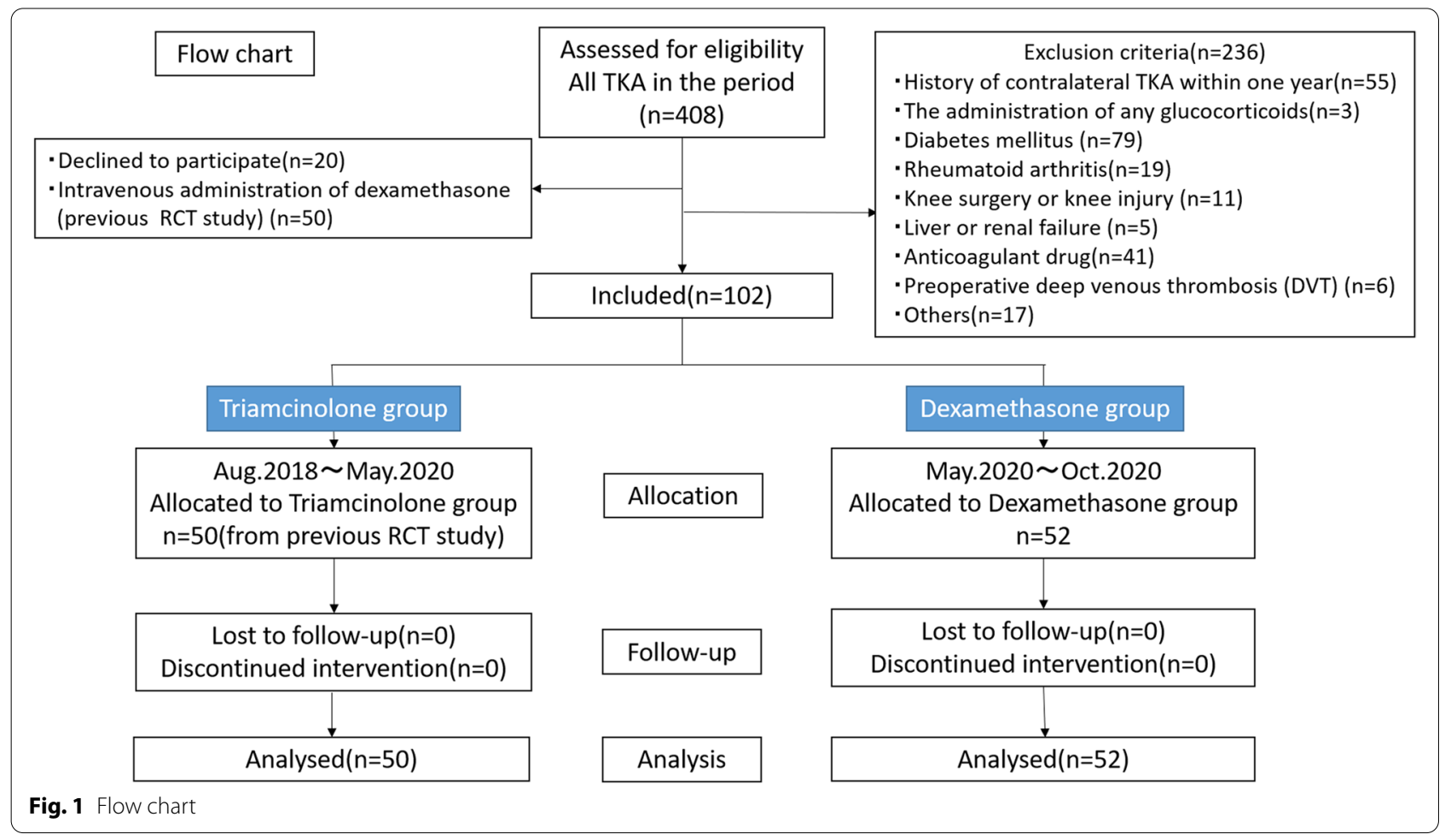


Table 1 Patient demographics and preoperative laboratory data

\begin{tabular}{llll}
\hline & Dexamethasone & Triamcinolone & $\boldsymbol{p}$ value \\
\hline Age (year) & $74.1 \pm 7.6$ & $72.0 \pm 6.2$ & 0.133 \\
Sex (M/F) & $9 / 43$ & $12 / 38$ & 0.468 \\
Height (cm) & $151.4 \pm 7.9$ & $154.0 \pm 9.2$ & 0.120 \\
Weight (kg) & $59.2 \pm 10.6$ & $61.4 \pm 9.7$ & 0.279 \\
Operative time (min) & $100 \pm 16$ & $101 \pm 15$ & 0.676 \\
FBG (mg/dL) & $102.9 \pm 9.2$ & $107.7 \pm 14.0$ & 0.041 \\
CRP (mg/dL) & $0.20 \pm 0.44$ & $0.24 \pm 0.57$ & 0.686 \\
flex-active ROM $\left(^{\circ}\right)$ & $122.8 \pm 15.4$ & $122.5 \pm 12.7$ & 0.902 \\
\hline
\end{tabular}

FBG Fasting Blood Glucose

ROM Range of Motion

Values are the mean \pm standard deviation differences in the number of patients who had a fever within $72 \mathrm{~h}$ postoperatively between the two groups (Table 2).

There were no significant differences in the nausea score between the two groups (Fig. 5). Five patients (9.6\%) vomited in the dexamethasone group, and 7 patients (14\%) vomited in the triamcinolone group, showing no significant differences. There were also no marked differences in the incidence of metoclopramide use between the two groups. (Table 2).

Fasting blood glucose levels the morning after surgery were significantly increased in both groups compared with before surgery (dexamethasone group: preoperatively $\quad 102.9 \pm 9.2 \mathrm{mg} / \mathrm{dl} \rightarrow$ postoperatively
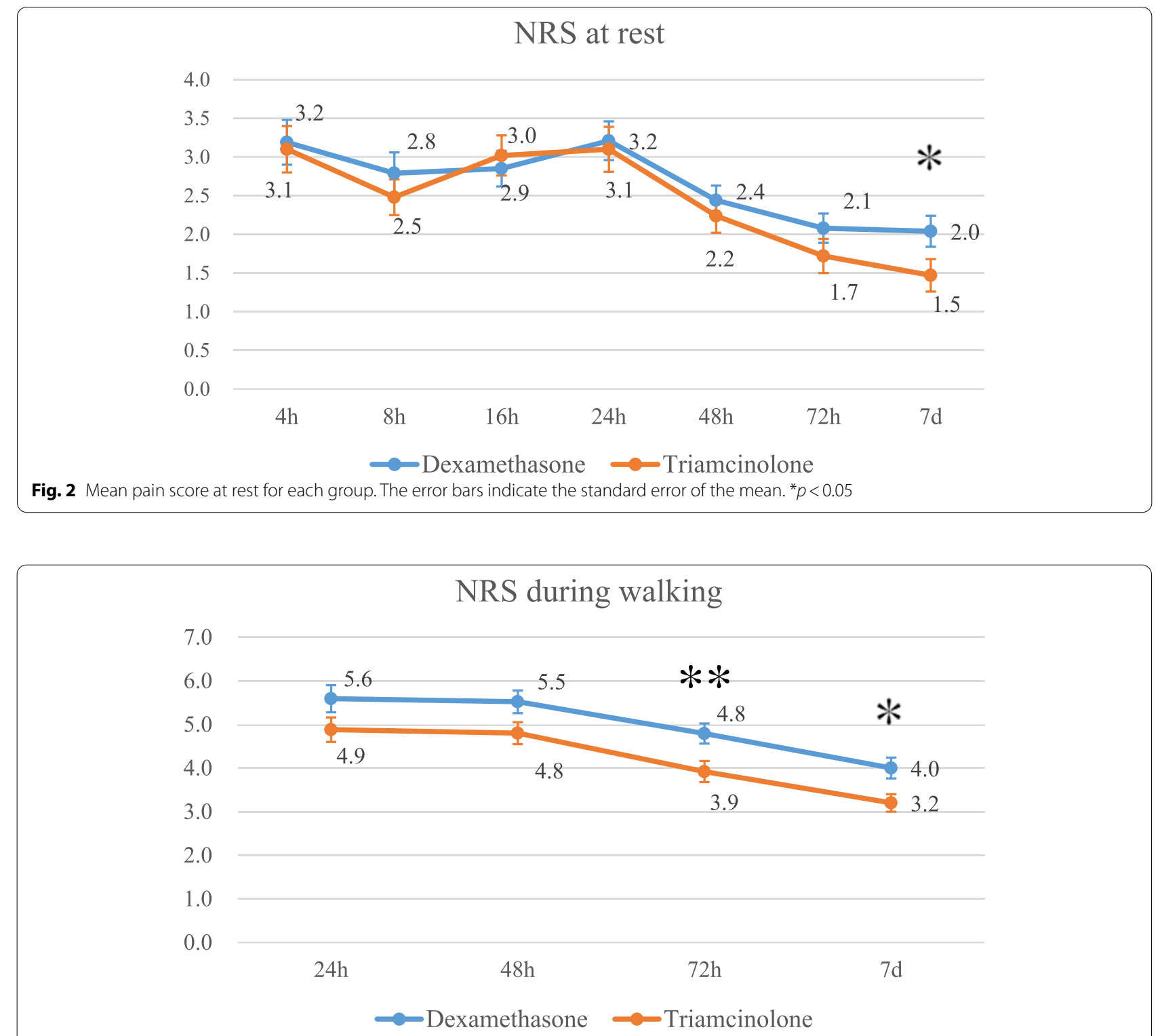

Fig. 3 Mean pain score during walking for each group. The error bars indicate the standard error of the mean. ${ }^{* *} p<0.01{ }^{*} p<0.05$ 
Table 2 The number of use of rescue analgesia and metoclopramide and the incidence of fever and vomiting

\begin{tabular}{llll}
\hline & Dexamethasone & Triamcinolone & p value \\
\hline Mean number of the uses of rescue analgesia & $1.3 \pm 0.8$ & $1.1 \pm 0.8$ & 0.330 \\
Number of patients who had a fever & $4(7.7 \%)$ & $2(4 \%)$ & 0.551 \\
Mean number of the uses of metoclopramide & $0.3 \pm 0.5$ & $0.3 \pm 0.5$ & 0.325 \\
Number of patients who had vomiting & $5(9.6 \%)$ & $7(14 \%)$ & 0.678 \\
\hline
\end{tabular}

Values are the mean \pm standard deviation

\section{$\mathrm{CRP}(\mathrm{mg} / \mathrm{dL})$}

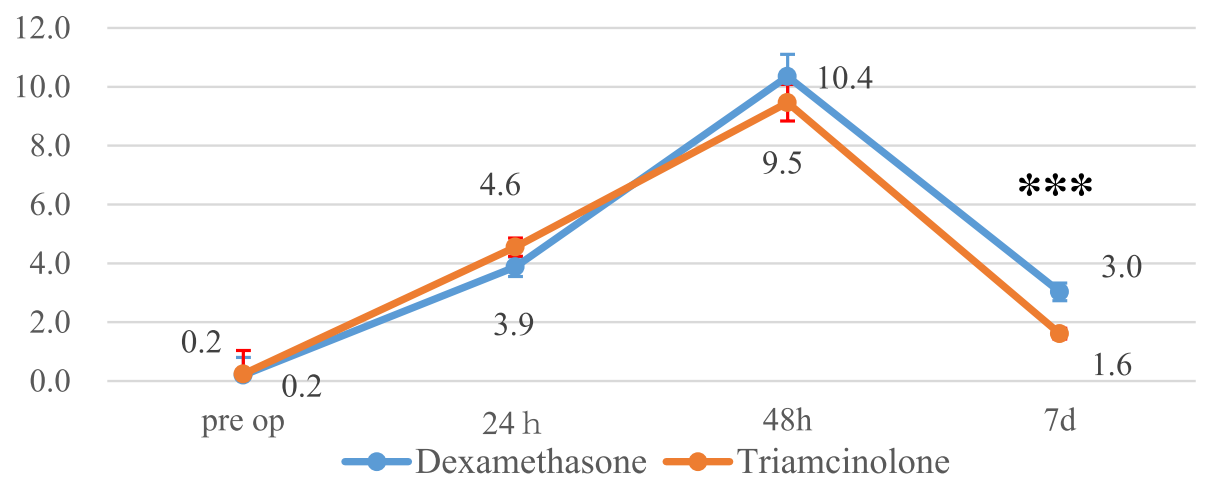

Fig. 4 Mean CRP for each group. The error bars indicate the standard error of the mean. ${ }^{* *} P<0.001$

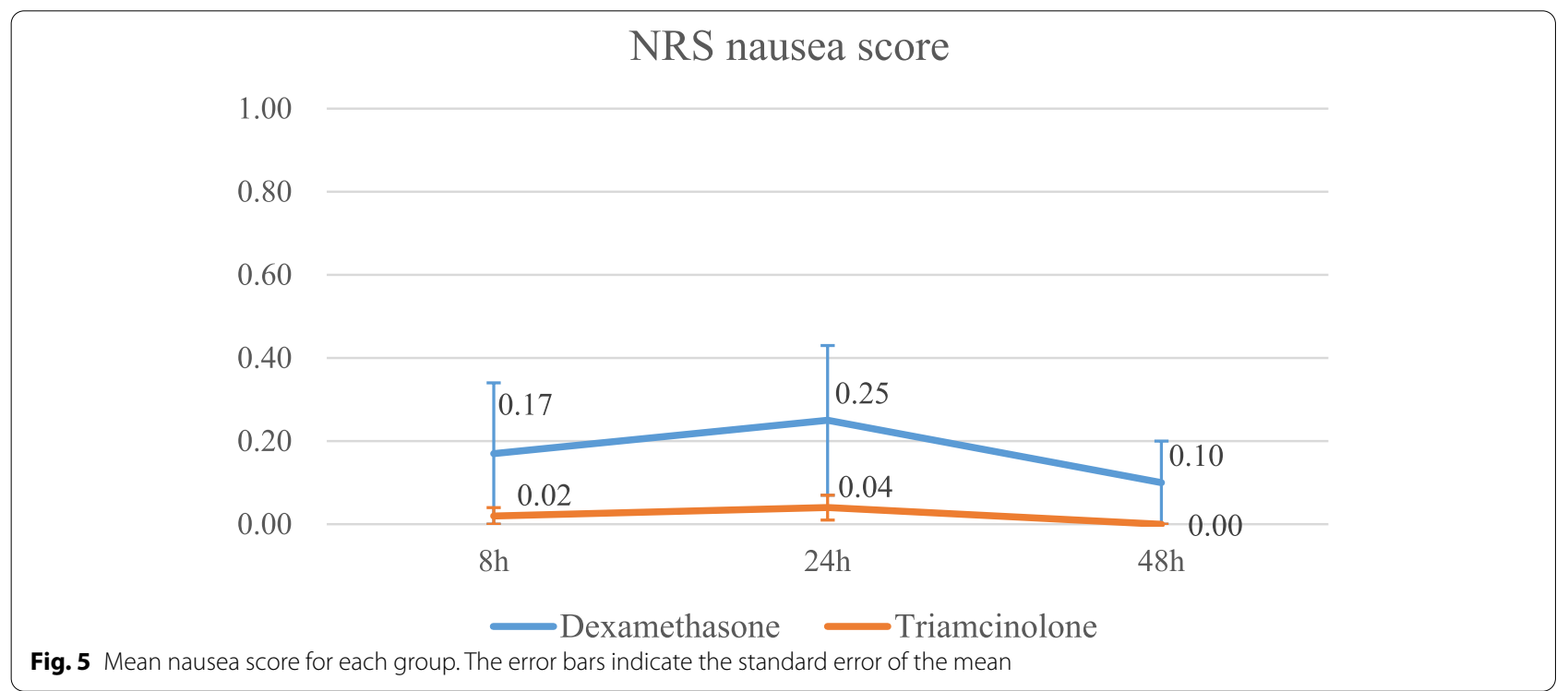

$123.8 \pm 14.3 \mathrm{mg} / \mathrm{dl}$; triamcinolone group: preoperatively $107.7 \pm 14.0 \mathrm{mg} / \mathrm{dl} \rightarrow$ postoperatively $125.4 \pm 15.7 \mathrm{mg} /$ $\mathrm{dl}$ : post hoc power 0.53$)$. However, there were no significant differences in the levels between the two groups after surgery (Fig. 6).

\section{Discussion}

The most important finding in this study was that the pain scores in the triamcinolone group were significantly lower than those in the dexamethasone group while walking at $72 \mathrm{~h}$ and both at rest and while walking at 


\section{Fasting blood glucose(mg/dL)}

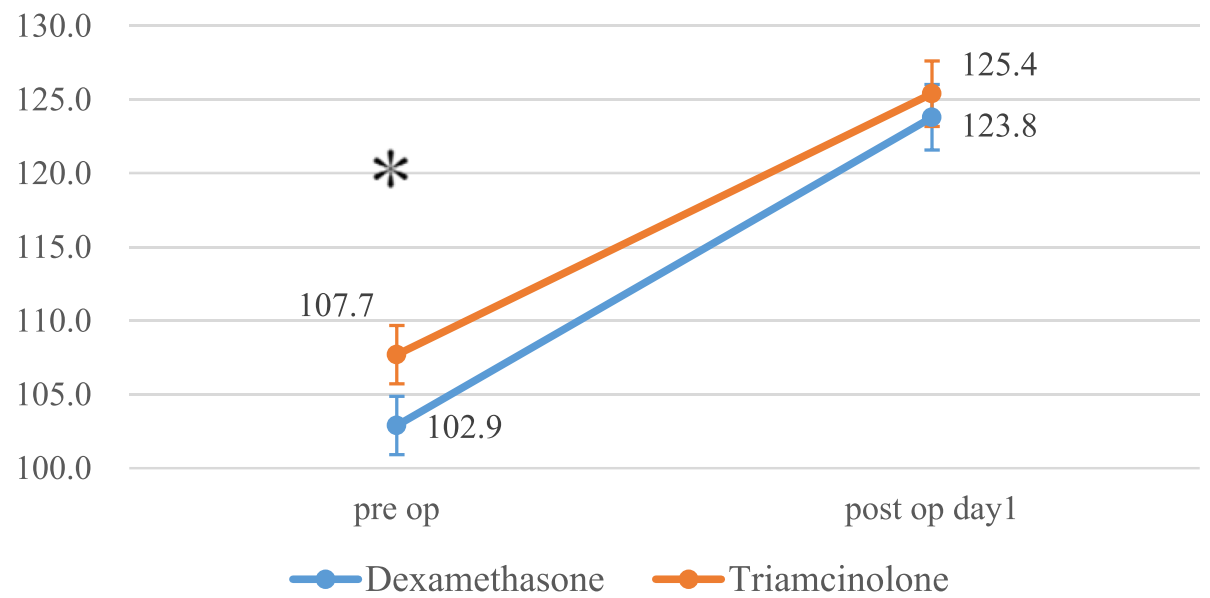

Fig. 6 Mean fasting blood glucose for each group. The error bars indicate the standard error of the mean. ${ }^{*} p<0.05$

7 days after surgery. In addition, the CRP levels in the triamcinolone group were significantly lower than those in the dexamethasone group at 7 days after surgery.

Periarticular administration of corticosteroids proved effective for reducing perioperative pain for TKA [1-3, 14-16]. Many different types of corticosteroids have been used for periarticular injection [17]. However, which is the most effective type of corticosteroid is unclear. To our knowledge, this study is the first to compare the effects of different types of corticosteroids delivered via periarticular administration following TKA.

Previous pharmacokinetic studies have shown that $8 \mathrm{mg}$ of dexamethasone is equivalent to $40 \mathrm{mg}$ of triamcinolone $[2,14,15]$. Dexamethasone is insoluble in water, has an average intraarticular duration of action of 8 days, and has a clinical dose of $8 \mathrm{mg}$ [18].. In contrast, triamcinolone acetonide is insoluble in water, has a clinical dose of $10-40 \mathrm{mg}$, and has a longer duration of action of 14 days [18-20]. In the present study, $40 \mathrm{mg}$ triamcinolone acetonide periarticular administration provided greater pain relief and more markedly reduced inflammation than $10 \mathrm{mg}$ dexamethasone, with a particular difference seen in the results from $72 \mathrm{~h}$ to 7 days. In addition, the CRP levels in the triamcinolone group were significantly lower than in the dexamethasone group at 7 days after surgery. Our findings showed that triamcinolone acetonide had a stronger long-term analgesic and antiinflammatory effect than dexamethasone in a clinical setting.

A postoperative fever after TKA is partly the result of the local and systemic release of inflammatory cytokines [21]. A previous study showed that 10 of 20 patients (50\%) had a fever of $>38.5^{\circ} \mathrm{C}$ for 3 days after TKA without glucocorticoid administration [21]. Another systematic review reported that 62 of 170 patients (36.5\%) had pyrexia $\left(>38.0^{\circ} \mathrm{C}\right)$ in the first 5 days following TKA without glucocorticoid administration [22]. In the present study, 4 of $52(7.7 \%)$ patients who were provided dexamethasone and 2 of 50 (4\%) who were provided triamcinolone acetonide had a fever $\left(>38.0^{\circ} \mathrm{C}\right)$ within $72 \mathrm{~h}$ after TKA. These rates were lower than those reported previously in studies without corticosteroid administration. Both dexamethasone and triamcinolone acetonide periarticular injections thus appear to have had antiinflammatory effects, and their effects were equivalent in the short term.

Another benefit of the administration of corticosteroids is the postoperative antiemetic effect. Most postoperative nausea occurs during the first $24 \mathrm{~h}$ after surgery, and the intravenous administration of dexamethasone effectively prevents postoperative nausea [2,3]. Periarticular administration also had a postoperative antiemetic effect [23]. Another study showed that periarticular injection of corticosteroids had a similar antiemetic effect to intravenous administration [9]. Our present study showed that the periarticular injection of corticosteroids reduced postoperative nausea and vomiting regardless of the type of corticosteroid, at least for dexamethasone and triamcinolone acetonide.

The effect of corticosteroids on postoperative hyperglycemia after TKA is controversial at present. Hyperglycemia of $>200 \mathrm{mg} / \mathrm{dL}$ increased the risk of superficial surgical site infection and wound complications [24, 25]. A previous study reported that there was no association between perioperative dexamethasone intravenous administration during arthroplasty and the risk of 
maximum postoperative hyperglycemia $>200 \mathrm{mg} / \mathrm{dl}$ [26].. However, in another previous study, the fasting blood glucose level on the morning following surgery in patients who received periarticular injection of triamcinolone acetonide was significantly higher than that in patients who received intravenous administration of dexamethasone [9]. In the present study, the fasting blood glucose level the morning following surgery was increased in both groups who received periarticular injection of triamcinolone or dexamethasone, although no patients had hyperglycemia $>200 \mathrm{mg} / \mathrm{dL}$. When administering periarticular injections, regardless of the type of corticosteroid, we should be alert for increased blood glucose levels.

Several limitations associated with the present study warrant mention. First, the period during which the two corticosteroids were selected was different. The lack of a control group in the same study period may over-estimate the results [27]. Second, a femoral nerve block was performed for all patients before TKA, which may have masked the pain scale in early the postoperative period. The analgesic effects of reduced pain due to a peripheral nerve block and periarticular injection have been reported to be similar for TKA [28]. Third, the pain scores in the triamcinolone group were significantly lower than those in the dexamethasone group, ranging from 0.4 to 0.9 at the NRS. However, the minimal clinically important difference (MCID) for the visual analog scale for pain was $16.1 \mathrm{~mm}$ for TKA with minimal detectable change [29]. These significant differences in pain score may not be clinically important differences.

\section{Conclusions}

Triamcinolone acetonide periarticular administration provided greater pain relief by more effectively reducing inflammation than dexamethasone. There were no significant differences in the control of the fasting blood glucose level or nausea between triamcinolone acetonide and dexamethasone.

\section{Abbreviations \\ TKA: Total knee arthroplasty; CRP: C-reactive protein; MCID: The minimal clini- cally important difference.}

\section{Acknowledgements}

Not applicable.

\section{Authors' contributions}

$\mathrm{AO}$ is responsible for data analyses and writing. $\mathrm{KH}$ is responsible for the study design, data collection and surgical procedures. MT is responsible for the study design and surgical procedures. HK assisted surgical procedures. SH and $\mathrm{HC}$ are responsible for the manuscript preparation. The authors read and approved the final manuscript.

\section{Funding}

The authors declare that they have no funding.

\section{Availability of data and materials}

The datasets used and/or analysed during the current study are available from the corresponding author on reasonable request.

\section{Declarations}

Ethics approval and consent to participate

The study design was approved by the appropriate ethics review board of Japan Community Health Care Organization Gunma Central Hospital.

We obtained informed consent from all study subjects.

All methods were performed in accordance with the relevant guidelines and regulations.

\section{Consent for publication}

Not applicable.

\section{Competing interests}

The authors declare that they have no competing interest.

\section{Author details}

${ }^{1}$ Department of Orthopaedic Surgery, Japan Community Health Care Organization Gunma Central Hospital, 1-7-13 Koun-cho, Maebashi, Gunma 371-0025, Japan. ${ }^{2}$ Department of Orthopaedic Surgery, Gunma University Graduate School of Medicine, 3-39-15 Showa-machi, Maebashi, Gunma 371-8511, Japan.

Received: 23 August 2021 Accepted: 17 January 2022

Published online: 05 February 2022

\section{References}

1. Backes JR, Bentley JC, Politi JR, Chambers BT. Dexamethasone reduces length of hospitalization and improves postoperative pain and nausea after total joint arthroplasty: a prospective, randomized controlled trial. J Arthroplast. 2013;28(8 Suppl):11-7.

2. Koh IJ, Chang CB, Lee JH, Jeon YT, Kim TK. Preemptive low-dose dexamethasone reduces postoperative emesis and pain after TKA: a randomized controlled study. Clin Orthop Relat Res. 2013;471(9):3010-20.

3. Xu H, Zhang S, Xie J, Lei Y, Cao G, Pei F. Multiple doses of perioperative dexamethasone further improve clinical outcomes after Total knee arthroplasty: a prospective, randomized, Controlled Study. J Arthroplasty. 2018;33(11):3448-54.

4. Chia SK, Wernecke GC, Harris IA, Bohm MT, Chen DB, Macdessi SJ. Periarticular steroid injection in total knee arthroplasty: a prospective, double blinded, randomized controlled trial. J Arthroplast. 2013;28(4):620-3.

5. Ikeuchi M, Kamimoto Y, Izumi M, Fukunaga K, Aso K, Sugimura N, et al. Effects of dexamethasone on local infiltration analgesia in total knee arthroplasty: a randomized controlled trial. Knee Surg Sports Traumatol Arthrosc. 2014;22(7):1638-43.

6. Kulkarni M, Mallesh M, Wakankar H, Prajapati R, Pandit H. Effect of methylprednisolone in periarticular infiltration for primary Total knee arthroplasty on pain and rehabilitation. J Arthroplast. 2019;34(8):1646-9.

7. Christensen CP, Jacobs CA, Jennings HR. Effect of periarticular corticosteroid injections during total knee arthroplasty. A double-blind randomized trial. J Bone Joint Surg Am. 2009;91(11):2550-5.

8. Tsukada S, Wakui M, Hoshino A. The impact of including corticosteroid in a periarticular injection for pain control after total knee arthroplasty: a double-blind randomised controlled trial. Bone Joint J. 2016;98-b(2):194-200.

9. Hatayama K, Terauchi M, Oshima A, Kakiage H, Ikeda K, Higuchi H. Comparison of intravenous and periarticular Administration of Corticosteroids in Total knee arthroplasty: a prospective, randomized controlled study. J Bone Joint Surg Am. 2021;103(4):319-25.

10. Li D, Wang Q, Zhao X, Luo Y, Kang P. Comparison of intravenous and topical dexamethasone for Total knee arthroplasty: a randomized doubleblinded controlled study of effects on dexamethasone administration route and enhanced recovery. J Arthroplasty. 2021;36(5):1599-606.

11. Hajialilo M, Ghorbanihaghjo A, Valaee L, Kolahi S, Rashtchizadeh N, Amirkhiz MB, et al. A double-blind randomized comparative study of 
triamcinolone hexacetonide and dexamethasone intra-articular injection for the treatment of knee joint arthritis in rheumatoid arthritis. Clin Rheumatol. 2016;35(12):2887-91.

12. Godshaw BM, Mehl AE, Shaffer JG, Meyer MS, Thomas LC, Chimento GF. The effects of Peri-operative dexamethasone on patients undergoing Total hip or knee arthroplasty: is it safe for diabetics? J Arthroplast. 2019;34(4):645-9.

13. Pang HN, Lo NN, Yang KY, Chong HC, Yeo SJ. Peri-articular steroid injection improves the outcome after unicondylar knee replacement: a prospective, randomised controlled trial with a two-year follow-up. J Bone Joint Surg Br. 2008;90(6):738-44.

14. Salerno A, Hermann R. Efficacy and safety of steroid use for postoperative pain relief. Update and review of the medical literature. J Bone Joint Surg Am. 2006;88(6):1361-72.

15. Samona J, Cook C, Krupa K, Swatsell K, Jackson A, Dukes C, et al. Effect of intraoperative dexamethasone on pain scores and narcotic consumption in patients undergoing Total knee arthroplasty. Orthop Surg. 2017;9(1):110-4.

16. Xu B, Ma J, Huang Q, Huang ZY, Zhang SY, Pei FX. Two doses of low-dose perioperative dexamethasone improve the clinical outcome after total knee arthroplasty: a randomized controlled study. Knee Surg Sports Traumatol Arthrosc. 2018;26(5):1549-56.

17. Xing LZ, Li L, Zhang LJ. Can intravenous steroid administration reduce postoperative pain scores following total knee arthroplasty?: a metaanalysis. Medicine (Baltimore). 2017;96(24):e7134.

18. Caldwell JR. Intra-articular corticosteroids. Guide to selection and indications for use. Drugs. 1996;52(4):507-14.

19. Dragoo JL, Danial CM, Braun HJ, Pouliot MA, Kim HJ. The chondrotoxicity of single-dose corticosteroids. Knee Surg Sports Traumatol Arthrosc. 2012;20(9):1809-14.

20. Stephens MB, Beutler Al, O'Connor FG. Musculoskeletal injections: a review of the evidence. Am Fam Physician. 2008;78(8):971-6.

21. Andres BM, Taub DD, Gurkan I, Wenz JF. Postoperative fever after total knee arthroplasty: the role of cytokines. Clin Orthop Relat Res. 2003:415:221-31.

22. Ghosh S, Charity RM, Haidar SG, Singh BK. Pyrexia following total knee replacement. Knee. 2006;13(4):324-7.

23. Yano T, Imaizumi T, Matsu-Ura H, Takahashi T. Relationship between dexamethasone added to periarticular anesthetic infiltration and postoperative nausea and vomiting following total knee arthroplasty under general anesthesia: a retrospective observational study. JA Clin Rep. 2020;6(1):66.

24. Hwang JS, Kim SJ, Bamne AB, Na YG, Kim TK. Do glycemic markers predict occurrence of complications after total knee arthroplasty in patients with diabetes? Clin Orthop Relat Res. 2015;473(5):1726-31.

25. Stryker LS, Abdel MP, Morrey ME, Morrow MM, Kor DJ, Morrey BF. Elevated postoperative blood glucose and preoperative hemoglobin $\mathrm{A} 1 \mathrm{C}$ are associated with increased wound complications following total joint arthroplasty. J Bone Joint Surg Am. 2013;95(9):808-14 s801-802.

26. Nurok M, Cheng J, Romeo GR, Vecino SM, Fields KG, YaDeau JT. Dexamethasone and perioperative blood glucose in patients undergoing total joint arthroplasty: a retrospective study. J Clin Anesth. 2017;37:116-22.

27. Morton $\mathrm{V}$, Torgerson DJ. Effect of regression to the mean on decision making in health care. Bmj. 2003;326(7398):1083-4.

28. Uesugi K, Kitano N, Kikuchi T, Sekiguchi M, Konno S. Comparison of peripheral nerve block with periarticular injection analgesia after total knee arthroplasty: a randomized, controlled study. Knee. 2014;21(4):848-52.

29. Danoff JR, Goel R, Sutton R, Maltenfort MG, Austin MS. How much pain is significant? Defining the minimal clinically important difference for the visual analog scale for pain after Total joint arthroplasty. J Arthroplast. 2018;33(7s):S71-5 e72.

\section{Publisher's Note}

Springer Nature remains neutral with regard to jurisdictional claims in published maps and institutional affiliations.

Ready to submit your research? Choose BMC and benefit from:

- fast, convenient online submission

- thorough peer review by experienced researchers in your field

- rapid publication on acceptance

- support for research data, including large and complex data types

- gold Open Access which fosters wider collaboration and increased citations

- maximum visibility for your research: over $100 \mathrm{M}$ website views per year

At BMC, research is always in progress.

Learn more biomedcentral.com/submissions 